\title{
Old age and cognition: Evaluation of a human short-term memory test with nonhuman primates and the memory-enhancing effects of nimodipine
}

\author{
S. D. LEVERE and T. E. LEVERE \\ North Carolina State University, Raleigh, North Carolina
}

\begin{abstract}
A matrix problem, identical to that used with demented humans, was used to quantify the shortterm memory capacities of five 33-year-old rhesus monkeys. Nimodipine at dosages of 1.0 and $3.0 \mathrm{mg} / \mathrm{kg}$ given orally before each daily training session significantly improved the monkeys' performance, but a $0.3-\mathrm{mg} / \mathrm{kg}$ dosage did not. These results are interpreted as evidence that short-term memory deficits in both demented humans and aged nonhuman primates may be assessed with identical techniques and that calcium imbalances may contribute to the cognitive deficits that can accompany age.
\end{abstract}

Recent data suggest that the dihydropyridine calcium channel blocker nimodipine may provide a possible treatment strategy for both the physiological and the functional consequences of brain pathology. For example, if the drug is given within $8-12 \mathrm{~h}$ following stroke, cell death caused by calcium overload of neural cells immediately peripheral to the ischemia can be reduced by up to $40 \%$ (Scriabine, Schuurman, \& Traber, 1989 ; see also Scriabine, Teasdale, Tettenborn, \& Young, 1991). The drug may also have certain functional consequences, since it facilitates behavioral recovery of both unlearned responses (Finger, 1993; Schuurman, Klein, Beneke, \& Traber, 1988; Schuurman \& Traber, 1989) and learned discriminations (LeVere, Brugler, Sandin, \& Gray-Silva, 1989), even when administered long after focal brain injury when neural survival is not an issue.

In the present investigation, we were also concerned with calcium regulation and brain pathology, but not with that pathology which results from direct, localized brain insult. Rather, our focus was on the dementias that may be associated with age and, in particular, with dysfunctions of what is commonly called short-term memory. In this regard, nimodipine has been tested with aged rabbits in a trace-conditioning learning paradigm (Deyo, Straube, \& Disterhoft, 1989), with aged rats in an eightarm radial maze paradigm (LeVere and Walker, 1991), and with aged nonhuman primates tested in a directbaited delayed response paradigm (Sandin, Jasmin, \& LeVere, 1990). Nimodipine improved short-term memory in all cases.

This research was supported by a gift from the Division of Preclinical Pharmacology, Miles Laboratories, Inc. to T.E.L. Correspondence should be addressed to T. E. LeVere, Behavioral Neurobiology Laboratory, Department of Psychology, Box 7801, North Carolina State University, Raleigh, NC 27695-7801.
Although these results are impressive in their consistency, they lack some face validity with respect to the human condition, since the behavioral tasks are not those typically used to assess demented humans. That is to say, because of the obvious differences in the behavioral abilities of animals and humans, the tasks used with each subject population are usually comparable only on conceptual grounds, if at all. Thus, what may benefit short-term memory as it is assessed in the aged animal may have little consequence for the aged human. Alternatively, rabbits, rats, and monkeys are notoriously poor at remembering word lists, so whatever suggestions may be obtained from the human literature are usually not suitable to investigations with behavioral animal models.

There is, however, one testing procedure for quantifying short-term memory that is difficult enough to be meaningful to humans and at the same time is within the information processing abilities of animals. This task is a spatial memory test which was used by Moss, Albert, Butters, and Payne (1986) to evaluate patterns of memory loss in human patients with Alzheimer's disease, Huntington's disease, and alcoholic Korsakoff's syndrome. While Moss et al. used a number of cue variations in this study to detect differences in the memory capacities of the different groups, the fundamental method remained the same. This involved showing the subject a board with 30 small dots arranged in a $5 \times 6$ matrix. The board was then blocked from view while one of the dots was covered with a stimulus item, after which the subject was allowed to see the board and was asked to point to the location of the stimulus item. The subject's view of the board was then blocked again, and a new stimulus item was added to the matrix. The subject was then allowed to see the matrix and asked to point to the new, added stimulus item. Testing continued in this manner until the subject could not remember which 
items had been previously seen and failed to point to the newly added stimulus item. Thus short-term memory was quantified by the number of items on the matrix when the subject responded incorrectly and did not select, or point to, the new stimulus item. The method is most elegant in its simplicity, and it successfully differentiated the memory capacities of the patient groups and nonpatient groups. What is perhaps more important, however, is that the test can be used directly with nonhuman subjects and may provide a paradigm and an animal model that have clear face validity with regard to the clinical evaluation of humans.

We report here the use of this matrix memory task to estimate the short-term memory capacities of aged rhesus monkeys. Our objective was to determine whether this task could be effectively used with nonhuman subjects and whether nimodipine's facilitation of short-term memory in animals could be extended to include a task that is sensitive to human dementias.

\section{METHOD}

\section{Subjects}

The subjects were 5 female rhesus monkeys over 33 years of age. The animals are housed in an approved primate colony which is temperature controlled and maintained on a 14:12-h day:night cycle. The lights-on period began at 10:00 a.m. and the animals began their behavioral tests at 5:30 p.m. For this procedure, the animals were tested 5 days per week and were provided with free access to water and approximately $80 \%$ of their normal food ration $24 \mathrm{~h}$ prior to each test day. Three of the animals had previously participated in the manually operated direct-baited delayed-response task used by Sandin et al. (1990).

\section{Apparatus}

The matrix apparatus was a vertical black plastic panel (12 in. high $\times 13$ in. wide) which contained eight guillotine doors measuring $2 \mathrm{in.} \mathrm{square}$ and arranged in two rows of four doors each. Each door was separated from the other doors in the row by 1 in., and the 2 rows were separated by 2 in. The doors were constructed of "smokey gray" translucent plastic with a flashlight-like reflector and a $28-\mathrm{V}$ bulb attached to the rear side. A small knob at the front bottom edge of each door allowed the monkey to raise the door. All doors could be individually illuminated and locked or unlocked. Behind each guillotine door was a 2 -in. square cubical compartment, which could be baited with a reward (small pieces of assorted fruits) that could be retrieved by the primate when it raised the guillotine door.

The monkey operated the apparatus through a set of vertical bars attached to its transport cage, which was itself attached to the frame of the matrix panel. To ensure consistent testing, all functions of the apparatus, except the baiting of the reward compartments, were controlled electrically through a set of switches and relays.

\section{Procedure}

The design was within subjects and followed the typical behavioral pharmacological protocol that we previously used with the manually operated WGTA task (Sandin et al., 1990). In particular, an animal's performance was stabilized, and then the behavioral effect of a drug dosage was assessed, after which the animal's performance was restabilized, followed by another assessment of a different drug dosage, and so on until the behavioral consequences of all drug dosages were evaluated. Provided that an animal's behavior is stabilized between each drug test-that is, its performance is neither improving nor deteriorating - this procedure has two significant advantages. First, each animal is its own control and the effects of a drug dosage can be evaluated with regard to the animal's immediately preceding "drug free" behavior. Second, any permanent consequences of a drug dosage can be ascertained by any change in the level of performance during the restabilization testing immediately following a drug dosage test. The latter advantage of the procedure requires, of course, a set period of drug testing to control for drug exposure at different dosages, and it requires that the stabilization test has a performance criterion to allow for the evaluation of drug-free performance.

In detail, our implementation of this procedure began by initially training the animals to open the guillotine doors to retrieve small pieces of fruit. When the animals were proficient at this, training continued with seven of the eight doors dark and locked and a single, randomly selected, door illuminated and unlocked. The monkeys then learned to respond only to the lighted door, which varied after each choice, and not to attempt to open unlighted (locked) doors. During this time, the interval between choices was varied between 1 and $10 \mathrm{sec}$ to determine an optimal interresponse interval that would maintain consistent performance during subsequent formal testing.

Formal testing consisted of five trials each day. A trial began after the compartments behind each guillotine door were baited. All but one of the doors were locked and dark; the exception was lighted and unlocked. When the monkey lifted this door, its light was extinguished and the animal was allowed to retrieve the fruit reward. The animal then released the door, which fell closed, and initiated a 2-sec interresponse interval. After this delay, the previously lighted door was once again lighted and unlocked along with a second door that was also illuminated and unlocked. The monkey was then allowed to choose between the previously chosen illuminated door, now unbaited, and the newly lighted door, which was baited. If the animal opened the newly lighted door (i.e., responded correctly), it was allowed to obtain the reward, and the trial continued as described above. That is to say, following each correct choice, a new door with a baited compartment was lighted and unlocked and added to the lighted doors that the monkey had to choose from on its next opportunity to respond. When the monkey opened a previously opened door (i.e., responded incorrectly), the trial was terminated and the number of doors opened before the monkey reopened a door was scored as a measure of the animal's short-term memory capacity. At the end of each trial, the empty food compartments were rebaited and the next trial begun.

The order of which particular doors were lighted and unlocked on a given trial was determined randomly, with two restrictions to minimize large spatial cues that could confound our evaluation of an animal's performance under the drug or no-drug conditions. First, a newly lighted door had to be adjacent to a previously lighted door either horizontally, vertically, or diagonally. Second, a maximum of two doors could be lighted in sequence in a given row, after which the next lighted door had to be in the other row. In short, each newly lighted correct door was always adjacent to a previously chosen door, and neither the top nor the bottom row of doors was favored.

The monkeys continued this training until the performance of the group became stabilized. Stabilized performance was defined for each monkey as occurring when the standard error of the mean number of doors opened during a day's training was less than $10 \%$ of the mean performance over the 5-day test week. The initial stabilization required approximately 6 weeks of training, after which the animals were tested for a 2 -week period after being given a particular dosage of nimodipine prior to each day's test. Immediately following a drug test, the animals were again restabilized without drug before the next drug dosage was tested for a 2-week period. While each drug dosage test was of fixed duration (i.e., 2 weeks), restabilization was determined by the monkeys' performance in order to evaluate any carry-over effects of the previous drug treatment. However, in practice, restabilization after each 2 -week drug 
test required only 1 week, and we detected no drug carry-over effects. This general procedure was continued until all animals had been tested on all drug dosages.

The doses of nimodipine used in the present research were 0.3 , 1.0 , and $3.0 \mathrm{mg} / \mathrm{kg}$. The drug was administered by placing the required amount of the drug for each animal in a cup formed from a pitted prune. The cup was then folded over at the top to make a closed container and given to the monkey $90 \mathrm{~min}$ prior to its daily test. Since prunes are quite favored by aged primates, all animals immediately consumed the fruit without apparent regard for the nimodipine. The order of drug testing was balanced within the limitations imposed by the small number of subjects. That is, on the first 2 -week drug test, 2 of the monkeys received the $1.0-\mathrm{mg} / \mathrm{kg}$ dosage and 3 received the $3.0-\mathrm{mg} / \mathrm{kg}$ dosage. On the second $2-$ week drug test, this was reversed, and 2 monkeys received the 3.0$\mathrm{mg} / \mathrm{kg}$ dosage while the other 3 received the $1.0-\mathrm{mg} / \mathrm{kg}$ dosage. On the third, and final, 2-week drug test, each animal was given $0.3 \mathrm{mg} / \mathrm{kg}$ of nimodipine before each day's test.

We opted to delay the test of the $0.3-\mathrm{mg} / \mathrm{kg}$ dosage to the last because we wished to be conservative in our detection of possible drug effects. That is, should our procedure not be as uncontaminated as we had hoped and should the animals' performance have improved over the course of the experiment independently of the drug, then this improvement in performance should have accrued to the lowest, most probably ineffective, drug dosage test. The results, however, show that this design consideration was unnecessary.

\section{RESULTS}

\section{General}

Throughout the experiment, we noted no general behavioral effects of nimodipine. Whether the animals were tested on no-drug control restabilization or on one of the drug dosages, all animals operated the apparatus with the same efficiency and with the same response latencies. Additionally, no general behavior changes were noted when the animals' cages were cleaned and the monkeys were given their food ration after a day's testing.

\section{Drug Tests}

Regarding nimodipine's effect on the short-term memory capacities of the monkeys, we first analyzed the animals' mean performances during each no-drug control stabilization week preceding each drug dosage test. A repeated measures analysis of variance (ANOVA) indicated that the animals did not perform differently during any of these weeks $[F(2,8)=4.15, p>.05]$, which established two things. First, we were in fact measuring short-term memory performance and not acquisition, as these concepts are usually defined. Second, none of the drug dosages had any carry-over or permanent effect on performance subsequent to the administration of each drug. Accordingly, the no-drug control stabilization weeks were pooled to form a single measure against which the different drug dosages were evaluated.

Figure 1 presents these general findings. The leftmost bar is the pooled, no-drug control stabilization data, while the right three bars respectively show the mean performance of the monkeys after being given $0.3,1.0$, and $3.0 \mathrm{mg} / \mathrm{kg}$ of nimodipine prior to each day's test. A repeated measures ANOVA computed on these data in-

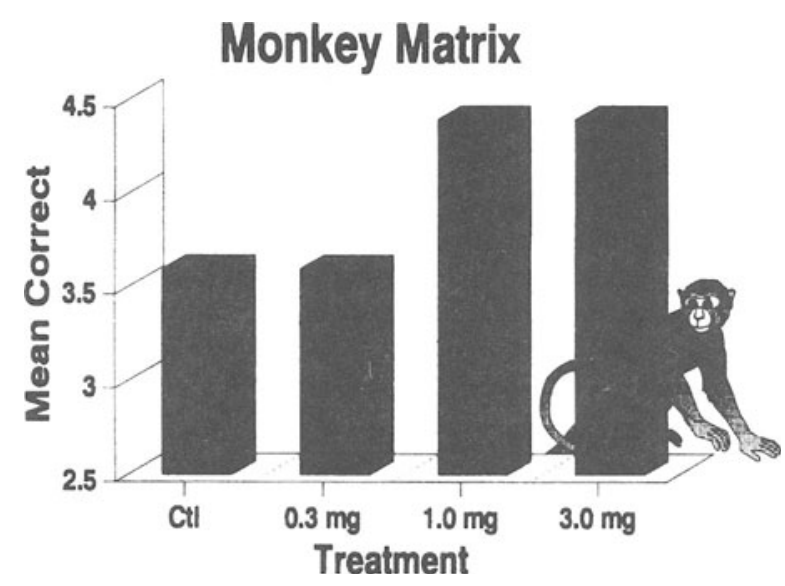

Figure 1. Mean number of doors raised by the monkeys before raising a door that they had previously opened, during control no-drug stabilization tests and each 2-week period of each drug test.

dicated that there were significant differences between the control and drug conditions $[F(3,12)=11.19, p<$ $.01]$. Tukey's critical difference score was $0.60(p<.05)$, indicating that the overall significant $F$ value was due to the $1.0-$ and $3.0-\mathrm{mg} / \mathrm{kg}$ dosages, which significantly improved the monkeys' performance while the $0.3-\mathrm{mg} / \mathrm{kg}$ drug dosage did not. The pooled control tests and $0.3-\mathrm{mg} / \mathrm{kg}$ drug dosage did not differ significantly from each other nor did the $1.0-\mathrm{mg} / \mathrm{kg}$ and $3.0-\mathrm{mg} / \mathrm{kg}$ drug dosage tests differ from each other.

Figures 2-4 show this in somewhat more detail. Each of these figures gives the mean daily performance of the monkeys on the control week preceding the respective 2 -week drug test $(0.3,1.0$, and $3.0 \mathrm{mg} / \mathrm{kg})$. Inspection of these graphs shows that (1) there were no consistent changes during the days of any of the control or drug tests and (2) the $0.3-\mathrm{mg} / \mathrm{kg}$ dosage had little effect on the primates' performance while the 1.0 - and $3.0-\mathrm{mg} / \mathrm{kg}$ dosages improved the monkeys' performance over the preceding control week. Statistically, we analyzed these

\section{Daily Performance Control \& $0.3 \mathrm{mg} / \mathrm{kg}$}

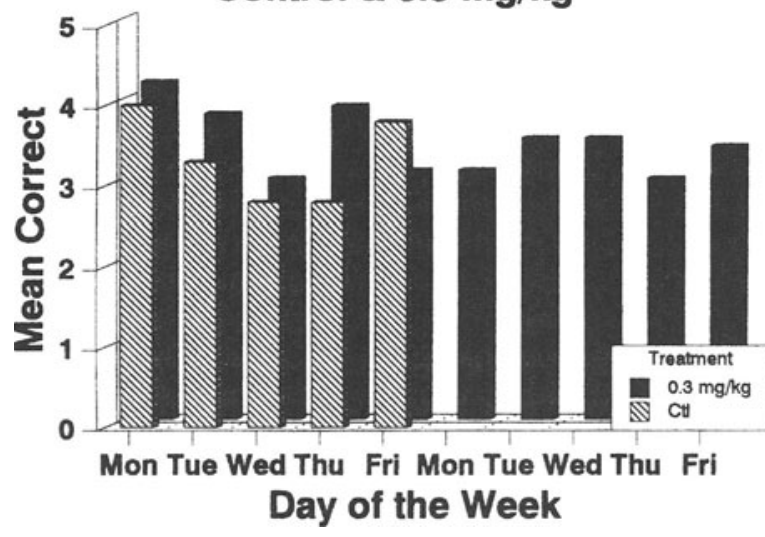

Figure 2. Mean daily performance of the monkeys during the immediately preceding control week and the $0.3-\mathrm{mg} / \mathrm{kg}$ 2-week drug test. 


\section{Daily Performance}

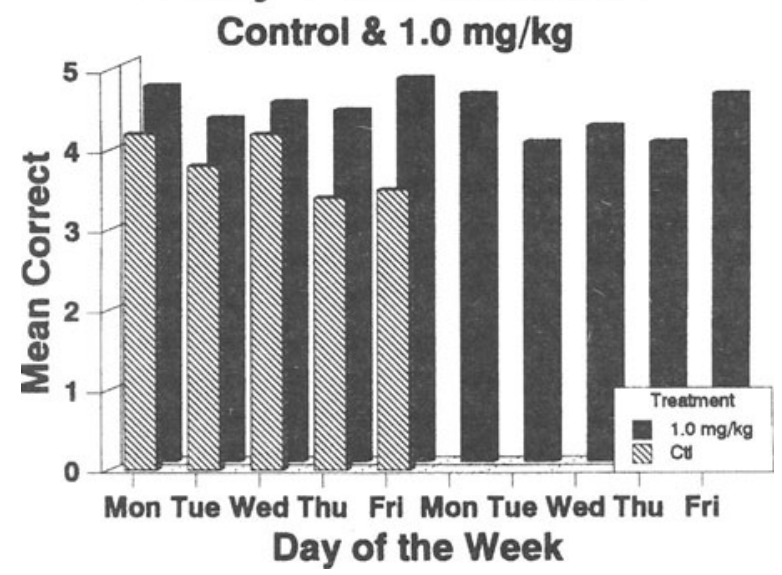

Figure 3. Mean daily performance of the monkeys during the immediately preceding control week and the $1.0-\mathrm{mg} / \mathrm{kg} 2$-week drug test.

\section{Daily Performace}

\section{Control \& $3.0 \mathrm{mg} / \mathbf{k g}$}

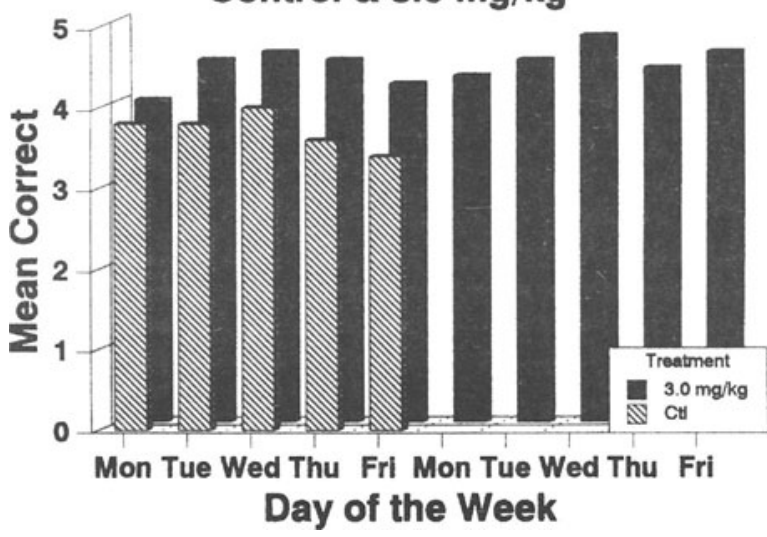

Figure 4. Mean daily performance of the monkeys during the immediately preceding control week and the $3.0-\mathrm{mg} / \mathrm{kg}$ 2-week drug test.

data with repeated measures ANOVAs (subject $\times$ days) on each control week preceding a drug dosage test and on the subsequent 2-week drug test. Only the control week preceding the $0.3-\mathrm{mg} / \mathrm{kg}$ drug test and the succeeding 2-week $0.3-\mathrm{mg} / \mathrm{kg}$ drug test reached conventional standards for rejecting the null hypothesis $[F(4,16)=$ $3.31, p<.05$, and $F(9,36)=3.56, p<.05$, respectively]. The other $F$ values for control and drug tests were not significant [respectively, $F(4,16)=2.51, F(9,36)=$ 1.26 , and $F(4,16)=1.18, F(9,36)=.073$, for the 1.0 $\mathrm{mg} / \mathrm{kg}$ and $3.0-\mathrm{mg} / \mathrm{kg}$ control and drug test weeks]. Unfortunately, with regard to the significant $F$ ratio during the control week preceding the $0.3-\mathrm{mg} / \mathrm{kg}$ drug test, Tukey's honest critical score $(1.32, p<.05)$ was unable to isolate which day(s) contributed to this significant $F$ value. For the $0.3-\mathrm{mg} / \mathrm{kg}$ drug test weeks, however,
Tukey's honest critical score indicated that on Wednesday of the 1st week of drug testing the animals performed worse than on any other day of the 2-week drug test. On the other days of this drug test, no reliable differences in performance were evident. We are unable to account for this slight drop in performance on the first Wednesday of the 2 -week $0.3-\mathrm{mg} / \mathrm{kg}$ drug test. However, the overall consistency of the monkeys' performance during all the control and drug tests suggests that this particular event was trivial.

Finally, we analyzed the performance of individual monkeys. These data are presented in Figures 5-7, which show the mean performance of each monkey during the control week and the immediately following 2-week drug dosage test for, respectively, the $0.3-, 1.0-$, and 3.0$\mathrm{mg} / \mathrm{kg}$ drug dosage tests. The data were analyzed with correlated $t$ tests for each control/drug dosage condition. The $0.3-\mathrm{mg} / \mathrm{kg}$ control versus drug dosage comparison for individual monkeys was not significant $[t(4)=$ $1.58]$, while the $1.0-$ and $3.0-\mathrm{mg} / \mathrm{kg}$ comparisons were significant $[t(4)=6.42$ and $t(4)=4.06$, respectively $]$.

\section{Individual Monkeys}

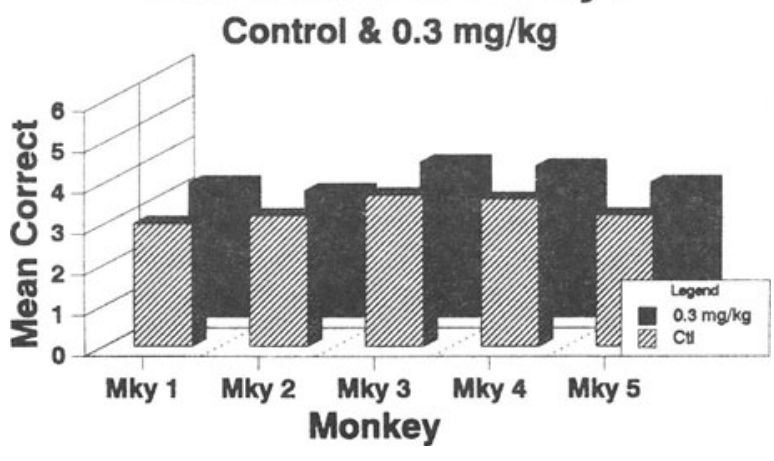

Figure 5. Mean performance of individual monkeys during the immediately preceding control week and the $0.3-\mathrm{mg} / \mathrm{kg}$ 2-week drug test.

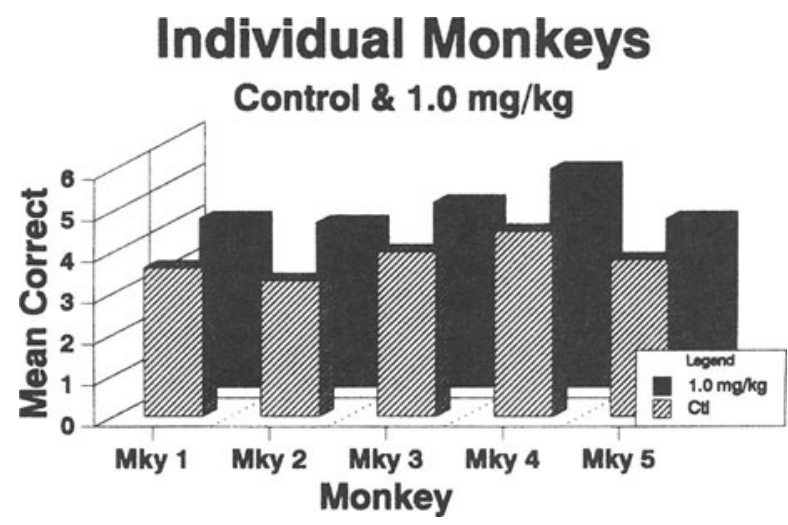

Figure 6. Mean performance of individual monkeys during the immediately preceding control week and the $1.0-\mathrm{mg} / \mathrm{kg} 2$-week drug test. 


\section{Individual Monkeys}

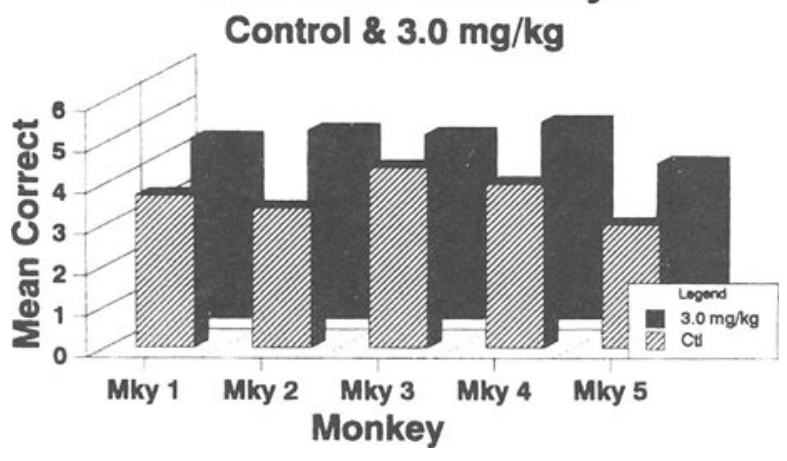

Figure 7. Mean performance of individual monkeys during the immediately preceding control week and the $3.0-\mathrm{mg} / \mathrm{kg}$ 2-week drug test.

Again the consistency of the data are compelling, and it appears that nimodipine can facilitate the short-term memory capacities of aged nonhuman primates and does so in a dose-related manner.

\section{DISCUSSION}

Although it is not an absolute certainty, more often than not short-term memory functions are one of the first cognitive processes to suffer the ravages of age. The results of the present research, however, add to a growing number of investigations which suggest that these memory dysfunctions may be addressed with pharmacological manipulations -in the present case, with drugs that affect calcium regulation. These findings thus appear to complement other investigations with aged rabbits (Deyo et al., 1989), aged rats (LeVere \& Walker, 1991; Schuurman et al., 1988; Schuurman \& Traber, 1989) and aged nonhuman primates (Sandin et al., 1990). Additionally, and perhaps more importantly, the present procedures are the same as those used with humans and thus provide some face validity to an animal model of age-related memory dysfunctions in humans.

It must, of course, be noted that this improvement in short-term memory was relatively modest in absolute terms. However, this improvement must be viewed in the context of the small number of animals that were tested and the nature of the task itself. In this regard, to achieve statistical significance the drug must not only affect performance but it must do so in an identical manner for each monkey. This was exactly the case for the 1.0 - and $3.0-\mathrm{mg} / \mathrm{kg}$ dosages, but not for the $0.3-\mathrm{mg} / \mathrm{kg}$ dosage. It is also important to remember that the monkeys' shortterm memory was evaluated within a procedure that was limited to seven responses per trial. In this context, an average improvement of but a single correct response is not trivial, as can be seen in Figure 8, which shows the percent improvement in short-term memory of animals on the $0.3-, 1.0-$, and $3.0-\mathrm{mg} / \mathrm{kg}$ drug dosages, in comparison with their performance during the preceding nodrug control week.
Given that nimodipine was effective in the present paradigm, there is a general question concerning whether the drug affected short-term memory. For example, attention deficits have been reported in some human Alzheimer's patients (Cossa, Della Sala, \& Spinnler, 1989; Freed, Corkin, Growdon, \& Nissen, 1989; Grady et al., 1989; Nebes \& Brady, 1989), and attention deficits may have contributed to the present results. Unfortunately, the matrix paradigm does not allow any clear dissociation of short-term memory and attention, if such is ever really possible. That is to say, if an individual does not attend to its environment, then environmental parameters will not be registered in, or accessed from, short-term memory. On the other hand, if short-term memory fails, attention becomes moot. Notwithstanding this, the present paradigm was designed to minimize attention factors insofar as these have been defined in animal research. For example, the addition of the correct, novel, door was always adjacent to previously selected doors in order to minimize gross spatial disparities that could impair the animals' attending to the total pattern of available choices. Additionally, and more importantly, the monkeys were required to respond directly to the stimulus array by raising a door to indicate their choice and retrieve a reward when the choice was correct. This is directly comparable to having a human point to a stimulus cue, and it satisfies the attention rules of stimulus-response contiguity and stimulus-reward contiguity as defined in research with nonhuman primates (LeVere, 1968a, 1968b; Meyer, Treichler, \& Meyer, 1965; Polidora \& Fletcher, 1964; Schuck, 1960). Thus, while it is always important to consider attention factors when investigating memorial deficits that are associated with aging, the present results more probably reflect nimodipine's effect on shortterm memory per se.

In more specific terms, the data should be counted with the growing evidence that cognitive functions affected by brain aging involve calcium regulation. Unfortunately, calcium's role in memory is poorly under-

\section{Percent Improvement Over Control}

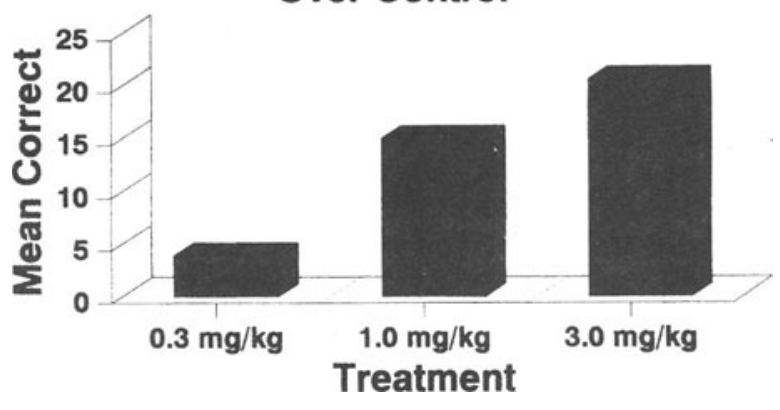

Figure 8. Mean percent improvement of short-term memory when the monkeys were given $0.3,1.0$, and $3.0 \mathrm{mg} / \mathrm{kg}$ of nimodipine, relative to the immediately preceding control week. 
stood, so it is difficult to be precise with regard to the molecular basis of these drug effects. Yet it is well established that nimodipine will block potential activated L-type calcium channels. It is also well established that nimodipine will reduce the neural cell death that is caused by calcium overload if the drug is administered within $8-12 \mathrm{~h}$ of cerebral ischemia (Scriabine et al., 1989; Scriabine et al., 1991).

However, reducing cell death is probably not the controlling factor in the present investigation. This is so because increasing the longevity of existing neural cells should only maintain existing short-term memory capacities, not improve them. Moreover, if reducing cell death caused the improvement in short-term memory, this improvement should outlast the actual drug treatment; but it did not. This, of course, does not mean that the present data contradict the findings that under appropriate circumstances nimodipine can reduce the cell death immediately surrounding an ischemic event. Rather, it means that the consequences, or the action, of the drug in the present research are more related to neural function as opposed to neural mortality.

To be sure, abnormal amounts of cell death are a defining characteristic of Alzheimer's disease. Yet, for the reasons given above, preventing or slowing the longterm demise of neural cells is probably not a viable explanation of the present findings. Rather, because of the transient improvements in short-term memory that were associated with drug treatment, it is much more likely that the drug somehow affected the functioning of neural cells. Again, it is difficult to be precise, but recent evidence suggests that malfunctions in calcium regulation may be a significant factor in Alzheimer's disease (see Davies \& Finch, 1987; Khachaturian, Cotman, \& Pettegrew, 1989). For example, Michaelis (1989) suggests that aged animals may be less efficient in maintaining normal internal calcium concentrations following the massive calcium influx that occurs with nerve depolarization. The fact that nimodipine can effectively block potential activated L-type calcium channels (Scriabine et al., 1989; Scriabine et al., 1991) suggests that the drug could potentially help to maintain normal calcium concentration pools in the aged brain. And if this is so, it is perhaps understandable why the drug improved the short-term memory of aged nonhuman primates but only did so when the drug was systemically active. This is a speculation, to be sure, but a speculation that is also compatible with Smith's (1987) observations concerning the kinetics of calcium regulation in the aged brain.

\section{REFERENCES}

Cossa, F., Della Sala, S., \& Spinnler, H. (1989). Selective visual attention in Alzheimer's and Parkinson's patients: Memory- and data-driven control. Neuropsychologia, 27, 887-892.

DAvIES, P., \& FINCH, C. E. (1987). Molecular neuropathology of aging. Cold Spring Harbor, MD: Cold Spring Harbor Laboratory.

Deyo, R. A., Straube, K. T., \& Disterhoft, J. F. (1989). Nimodipine facilitates associative learning in aging rabbits. Science, 243, 809-811.
Finger, S. (1993). Nimodipine and recovery from focal brain lesions. In Drugs in Development: $\mathrm{Ca}^{2+}$ Antagonists in the CNS [Special issue]. Drugs in Development, 2, 379-393.

Freed, D., Corkin, S., Growdon, J., \& Nissen, M. (1989). Selective attention and Alzheimer's disease: Characterizing cognitive subgroups of patients. Neuropsychologia, 27, 325-339.

Grady, C., Grimes, A., Patronas, N., Sunderland, T., Foster, N., \& RAPOPORT, S. (1989). Divided attention, as measured by dichotic speech performance, in dementia of the Alzheimer type. Archives of Neurology, 46, 317-320.

Khachaturian, Z. S., Cotman, C. W., \& Pettegrew, J. E. (Eds.) (1989). Calcium, membranes, aging, and Alzheimer's disease (Annals of the New York Academy of Sciences, Vol. 568). New York: New York Academy of Sciences.

LeVere, T. E. (1968a). Cue size and learning set performance with S-R induced sampling biases eliminated. Journal of Comparative \& Physiological Psychology, 65, 362-365.

LEVERE, T. E. (1968b). The failure of stimulus-reinforcement spatial discontiguity to influence performance under optimal conditions of stimulus sampling. Psychonomic Science, 11, 179-180.

LeVere, T. E., Brugler, T., SANdin, M., \& Gray-Silva, S. (1989). Recovery of function after brain damage: Facilitation by the calcium entry blocker nimodipine. Behavioral Neuroscience, 103, 561-565.

LeVere, T. E., \& WALKER, A. (1991). Aging and cognition: Enhancement of recent memory in rats by the calcium channel blocker nimodipine. Neurobiology of Aging, 13, 63-66.

Meyer, D. R., Treichler, F. R., \& Meyer, P. M. (1965). Discrete-trial training techniques and stimulus variables. In A. M. Schrier, H. F. Harlow, \& F. Stollnitz (Eds.), Behavior of nonhuman primates (Vol. 1., pp. 1-49). New York: Academic Press.

MichaELIS, M. L. (1989). $\mathrm{Ca}^{2+}$ handling systems and neuronal aging. In Z. S. Khachaturian, C. W. Cotman, \& J. W. Pettegrew (Eds.), Calcium, membranes, aging, and Alzheimer's disease (Annals of the New York Academy of Sciences, Vol. 568, pp. 89-94). New York: New York Academy of Sciences.

Moss, M. B., Albert, M. S., Butters, N., \& Payne, M. (1986). Differential patterns of memory loss among patients with Alzheimer's disease, Huntington's disease, and alcoholic Korsakoff's syndrome. Archives of Neurology, 43, 239-246.

Nebes, R., \& Brady, C. (1989). Focused and divided attention in Alzheimer's disease. Cortex, 25, 305-315

Polidora, V. J., \& Fletcher, H. J. (1964). An analysis of the importance of S-R spatial contiguity for proficient primate discrimination performance. Journal of Comparative and Physiological Psychology, 57, 224-230.

Sandin, M., JASMin, S., \& LeVERe, T. E. (1990). Aging and cognition: Facilitation of recent memory in aged nonhuman primates by nimodipine. Neurobiology of Aging, 11, 573-575.

SCHUCK, J. R. (1960). Pattern discrimination and visual sampling by the monkey. Journal of Comparative \& Physiological Psychology, 53, 251-255.

Schuurman, T., Klein, H., Beneke, M., \& Traber, J. (1988). Nimodipine and motor deficits in the aged rat. Neuroscience Research Communications, 1, 9-15.

Schuurman, T., \& Traber, J. (1989). Old rats as an animal model for senile dementia: Behavioral effects of nimodipine. In M. Bergener \& B. Reisberg (Eds.), Diagnosis and treatment of senile dementia (pp. 295-307). Berlin: Springer-Verlag.

Scriabine, A., Schuurman, T., \& Traber, J. (1989). Pharmacological basis for the use of nimodipine in central nervous system disorders. FASEB, 3, 1799-1806.

Scriabine, A., Teasdale, G. M., Tettenborn, D., \& Young, W. (Eds.) (1991). Nimodipine: Pharmacological and clinical results in cerebral ischemia. Berlin: Springer-Verlag.

SMITH, D. O. (1987). Non-uniform changes in nerve-terminal calcium homeostasis during aging. Neurobiology of Aging, 8, 366-368.

(Manuscript received May 10, 1993; revision accepted for publication December 21, 1993.) 